\title{
Histopatología de hojas de tomate inoculadas con Xanthomonas campestris pv vesicatoria
}

\author{
AM Alippi \\ Universidad Nacional de La Plata , Facultad de Agronomía, \\ Comisión de Investigaciones Científicas (Prov Bs As) y Cátedra de Fitopatología, calles 60 y 119, cc 31, 1900 La Plata, Argentina
}

(Recibido el 4 de julio de 1991; aceptado el 31 de octubre de 1991)

\begin{abstract}
Resumen - Se estudió la infección de Xanthomonas campestris pv vesicatoria en hojas de tomate por medio de microscopía óptica y electrónica de barrido. Se determinó que la bacteria penetra en el hospedante por los estomas y se localiza y multiplica en las cámaras subestomáticas que sirven como sitios de supervivencia. Adicionalmente, también penetraría por las bases de los tricomas deteriorados. Luego, las bacterias colonizan los espacios intercelulares del parénquima esponjoso y, al alcanzar las cámaras subestomáticas (no invadidas previamente), se multiplican abundantemente y son expulsadas, aglutinadas en un sustancia de naturaleza mucosa, dando origen a nuevas fuentes de inóculo.

Tras la inoculación, se notó una mayor concentración de células bacterianas en la cara inferior de las hojas. Los estomas y las cámaras subestomáticas fueron el nicho ecológico preferido por el patógeno para la posterior colonización del hospedante.
\end{abstract}

Xanthomonas campestris pv vesicatoria / Lycopersicon esculentum = tomate / microscopio electrónico de barrido / histopatología

Summary - Histopathology of tomato leaves inoculated by Xanthomonas pv vesicatoria. Xanthomonas campestris pv vesicatoria infection was followed by light and scanning electron microscopy. Bacteria entered leaf tissue through stomata and multiplied in substomatal chambers which are additional survival sites. The pathogen could also enter through the open base of trichomes. X c pv vesicatoria colonized the intercellular spaces of spongy parenchyma and could reach the uninvaded substomatal chambers and, after extensive multiplication, masses of bacterial cells, agglutinated in a mucous substance, extruded through stomata being the cause of secondary sources of inoculum. Abaxial leaf surfaces contained more bacteria than adaxial tomato leaf surfaces. Stomata and substomatal chambers were the preferred ecological niches of $\mathrm{X} c \mathrm{pv}$ vesicatoria before tissue colonization.

Xanthomonas campestris pv vesicatoria / Lycopersicon esculentum = tomato / scanning electron microscope / histopathology

\section{INTRODUCCIÓN}

La mancha bacteriana del tomate y pimiento, ocasionada por Xanthomonas campestris pv vesicatoria (Doidge) Dye produce significativas reducciones del rendimiento y de la calidad de los frutos, siendo los daños verdaderamente graves bajo condiciones de alta humedad relativa, lluvias prolongadas y temperaturas cercanas a los $24{ }^{\circ} \mathrm{C}$ (Hayward y Waterston, 1964).

Se han efectuado numerosos estudios de microscopia electrónica en otras enfermedades de origen bacteriano que producen manchas en hojas Y/o frutos: Xanthomonas campestris pv pruni (Miles et al, 1977; Duplessis, 1990); Xc pv manihotis (Verdier et al, 1990); $X c \mathrm{pv}$ oryzae (Mew et al, 1984; Tsuno y Wakimoto, 1988, 1989; Guo y Leach, 1989); $X c \mathrm{pv}$ citri (Lawson et al, 1989); Pseudomonas syringae pv tomato (Devash et al, 1980; Bashan et al, 1981; Getz et al, 1983; Perez et al, 1987); $P$ s pv syringae (Roos y Hattingh, 1987a, 1987b; Mansvelt y Hattingh, 1987, 1989; Hattingh et al, 1989); etc, pero no existen datos de microscopía electrónica de barrido sobre la penetración de $X c \mathrm{pv} v e$ sicatoria ni sobre su comportamiento histopatológico en tomate, con excepción del trabajo de Ramos y Volin (1987) sobre la relación existente entre apertura estomática y frecuencia de infección en distintas especies de Lycopersicon inoculadas con $X c$ pv vesicatoria. 
Los objetivos del presente trabajo fueron determinar el nicho ecológico preferido por el patógeno para penetrar al hospedante y evaluar las formas de colonización e infección de los tejidos vegetales y los mecanismos de diseminación posterior.

\section{MATERIALES Y MÉTODOS}

\section{Cepas bacterianas}

Se emplearon 42 cepas de Xanthomonas campestris pv vesicatoria (Doidge) Dye aisladas de diferentes híbridos y variedades de tomate (Lycopersicon esculentum $L$ ) que presentaban síntomas de la enfermedad.

Los aislamientos se efectuaron de acuerdo con la técnica de Hayward (1983) sobre placas de agar sucrosa peptona (SPA) (Hayward, 1960).

\section{Técnica de inoculación y muestreo}

Se emplearon suspensiones bacterianas en agua destilada estéril de las cepas 63T; 75T y 76T, las cuales habian manifestado previamente el mayor grado de virulencia (Grado 5) de acuerdo con la escala de Vakili (Vakili, 1967). La concentración bacteriana fue del orden de $10^{7} \mathrm{cel}^{\mathrm{ml}}{ }^{-1}$, no se empleó tensioactivo ni lesión de los tejidos y se aplicó en forma de pulverización.

Se utilizaron plantas de tomate de los híbridos: "Carmelo" y "Leo" de 5 semanas de edad que se mantuvieron en cámara húmeda (HR $=100 \%)$ durante $48 \mathrm{~h}$ a partir de la inoculación y luego se llevaron a invernáculo con temperaturas de $25-26^{\circ} \mathrm{C}$ diurnas y 18-20 ${ }^{\circ} \mathrm{C}$ nocturnas.

\section{Técnica de transparencia para microscopia óptica}

Los muestreos se realizaron a las $24 \mathrm{~h}$ de la inoculación y luego, a intervalos de $48 \mathrm{~h}$ hasta la aparición de síntomas en ambas caras de la hoja.

Se cortaron trozos de $7 \mathrm{~mm} \times 7 \mathrm{~mm}$ de limbo foliáceo y se sometieron a los siguientes tratamientos:

- Fijación durante 48 h en Formol-Acido acéticoAlcohol (FAA) (Johansen, 1940)

- 3 lavados en agua destilada (30 min cada uno)

- Aclarado en hidrato de cloral en agua destilada (5/2) durante $24 \mathrm{~h}$, previo secado con papel de filtro

- 3 enjuagues con agua destilada ( 30 min cada uno)

- Pasaje por ácido clorhídrico al 10\% durante 30 min (para eliminar los cristales de oxalato de calcio de las células parenquimáticas presentes en las hojas de
Solanaceae los cuales dificultan la visión por transparencia)

- 3 lavados en agua destilada ( 30 min cada uno)

- Tinción con solución acuosa de safranina durante $30 \mathrm{~min}$

- Enjuague con glicerina (40 $\mathrm{min}$ )

Luego de este proceso, los trozos se montaron en glicerina y se observaron con 150 y 600 aumentos.

\section{Técnicas para microscopia electrónica de barrido (SEM)}

Se cortaron trozos de $6 \mathrm{~mm} \times 6 \mathrm{~mm}$ de folíolos de plantas inoculadas y testigos y se muestrearon a los 30 min y a las 2 y 20 hs de la inoculación y luego, a intervalos diarios hasta la aparición de sintomas visibles y hasta 21 días tras la inoculación. Se efectuaron 2 repeticiones de la cara superior y 2 de la cara inferior de cada una de las muestras y se emplearon 2 métodos diferentes para preparar las mismas:

\section{Por congelación}

Al estado fresco, luego de $1 \mathrm{~h}$ de congelación a $-20^{\circ} \mathrm{C}$ (Petrolini et al, 1986; Verdier et al, 1990).

\section{Por fijación con glutaraldehído}

Las muestras se fijaron en solución de glutaraldehído al 5\% tamponado en tampón fosfato $0,2 \mathrm{~mol}^{-1} \mathrm{a} \mathrm{pH}$ 7,4 durante $14 \mathrm{~h}$ a $4{ }^{\circ} \mathrm{C}$ (Mansvelt y Hattingh, 1987); se deshidrataron en una serie de acetonas $(50 \%$, $75 \%, 90 \%$ y $100 \%$ ) durante 15 min en las 3 primeras y 30 min en la última.

En ambos casos, las muestras se metalizaron al vacío con una capa de oro de $1 \mu \mathrm{m}$ de espesor y se observaron con un microscopio electrónico Jeol Scanning JSM-T 100, efectuándose un barrido total de cada superficie.

\section{Técnicas para la determinación de actividad enzimática in vitro}

Para determinar la degradación de celulosa se empleó el medio CM-3 (Liao y Wells, 1987) con una concentración de carboximetil celulosa del $3 \%(p / v)$, utilizando solución alcohólica de Rojo Congo al 0,5\% como colorante y sol $1 \mathrm{~mol}^{-1}$ de $\mathrm{NaCl}$ como aclarante.

La utilización de celobiosa (compuesto intermedio de la degradación de celulosa) como única fuente carbonada se evaluó en el medio $\mathrm{D}_{5}$ (Kado y Heskett, 1970).

La actividad lipolítica se determinó por la hidrólisis del Tween 80 en el medio de Sierra (Sierra, 1957). 
En los 3 medios, se probaron las 42 cepas de $X c$ pv vesicatoria aisladas de tomate.

\section{RESULTADOS}

\section{Microscopía óptica}

Mediante la técnica de observación por transparencia, se comprobó que a partir de las $24 \mathrm{~h}$ de la inoculación y, durante 2 días, las bacterias se localizaron principalmente sobre los estomas $y$ dentro de las cavidades subestomáticas de la cara abaxial de la hoja. Los estomas fueron la única vía de penetración bacteriana.

A los 12 días, las paredes de las células del parénquima esponjoso aparecieron engrosadas y necrosadas y se observaron bacterias en los espacios intercelulares del parénquima foliáceo.

A los 14 días, las células epidérmicas de la zona supra-adyacente a la lesión, mostraron sus paredes engrosadas y oscurecidas (fig 1) y, en correspondencia con el área dónde se localizó la mancha, las células del clorénquima se observaron necrosadas y con sus paredes muy engrosadas (fig 2). Ya había síntomas visibles de la enfermedad en ambas caras de las hojas.

\section{Microscopía electrónica de barrido}

El material tratado por congelación, preservó mejor las estructuras vegetales, pero las bacterias aparecieron algo deformadas. Con el tratamiento de fijación y deshidratación con glutaraldehído y acetona, las bacterias mantuvieron su forma pero el tejido vegetal perdió su turgencia original.

A los $30 \mathrm{~min}$ de la inoculación, las bacterias aparecieron dispersas sobre la superficie de las hojas. A las $2 \mathrm{~h}$, se observaron bacterias en mayor proporción en las proximidades de los estomas de la cara adaxial (fig 3), pero aún no llegaban a la cara inferior. No se observaron bacterias sobre la superficie foliácea de los testigos.

A las $20 \mathrm{~h}$ no se visualizaron bacterias en la cara superior de las hojas, pero se encontraron concentradas sobre los estomas de la cara inferior (fig 4) y, en mayor número en la base de los tricomas y dentro de los tricomas deteriorados (áreas colapsadas) (fig 5).

A los 3 días, no hubo bacterias visibles sobre la superficie de las hojas inoculadas en ninguno
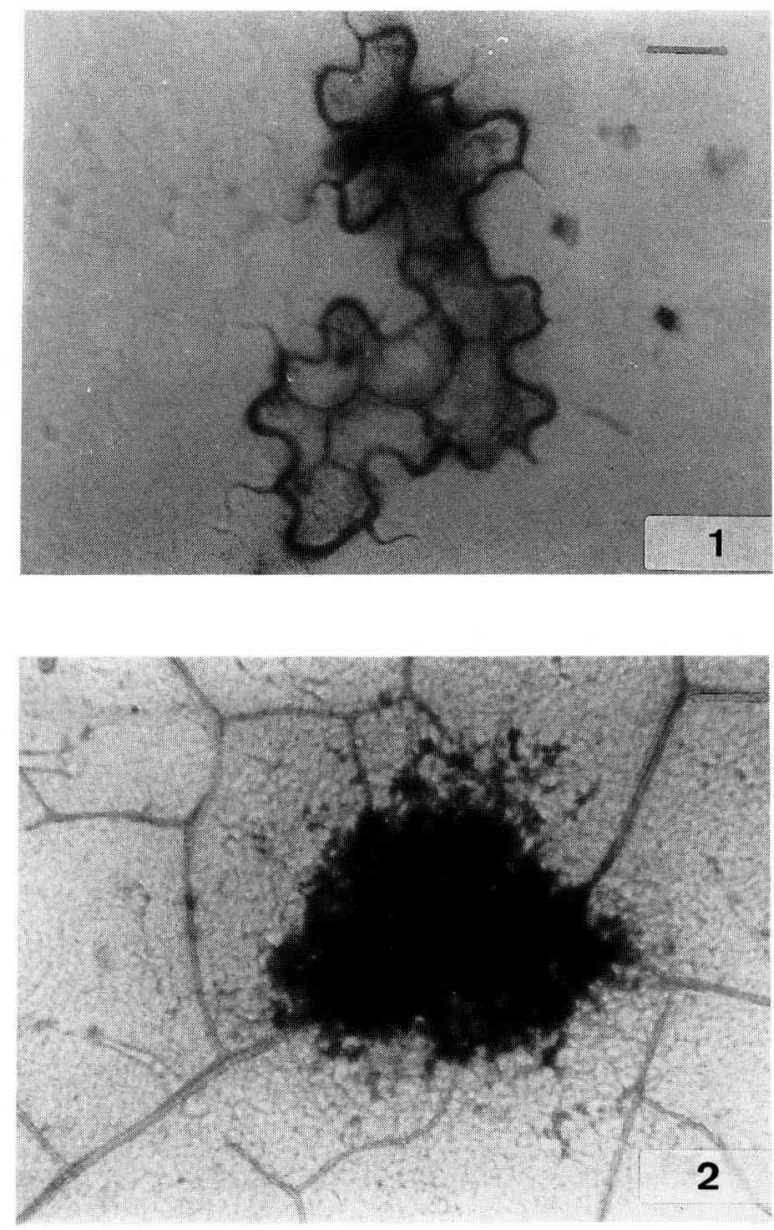

Figs 1-2. Fotografías de microscopía óptica de hojas de tomate inoculadas con Xanthomonas campestris pv vesicatoria, vistas por transparencia:

Fig 1. Células epidérmicas de la zona adyacente a la lesión con sus paredes engrosadas y colapsadas, a los 14 dias. Escala barra: $100 \mu \mathrm{m}$.

Flg 2. Células del clorénquima foliáceo necrosadas, en el área dónde se localiza la lesión. Escala: barra $100 \mu \mathrm{m}$.

de los campos observados de las muestras analizadas.

A los 6 días, se observaron masas bacterianas emergiendo de las cavidades subestomáticas a través de los estomas y aglutinadas en un material mucoso (fig 6). Dicho exudado mucoso, posiblemente de naturaleza hidrocarbonada de origen bacteriano (Huang, 1986) apareció en correspondencia con las lesiones de la cara abaxial y también se observó en las cercanías de las nervaduras y sobre ellas. En la cara adaxial, no se observaron síntomas macroscópicos ni tampoco bacterias.

A los 8 días, los tejidos vegetales se alteraron comenzando a fracturarse y desintegrarse $y$ apareció un material extraño, de aspecto granuloso, posiblemente de origen vegetal (fig 7). 

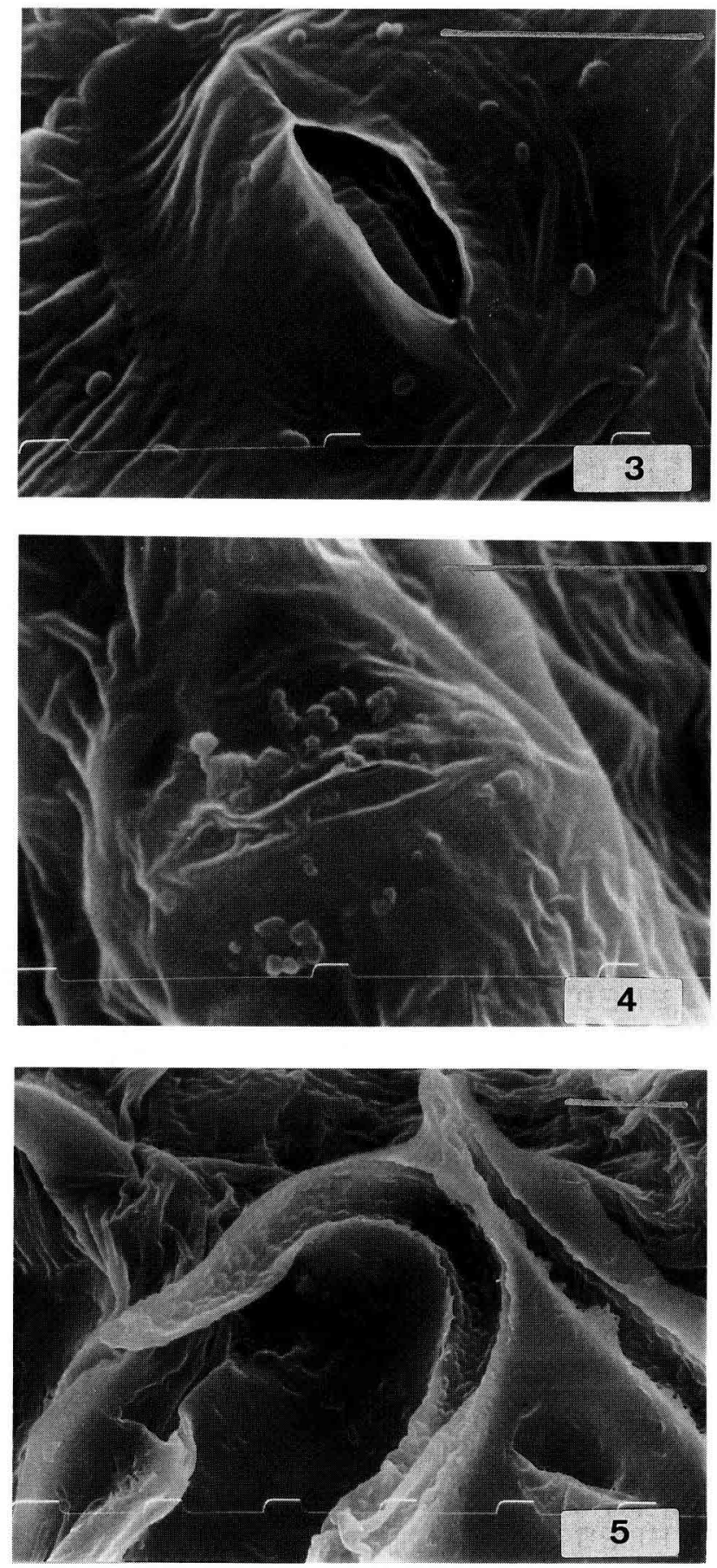

Figs 3-10: Fotografías de microscopio electrónico de barrido de hojas de tomate inoculadas con $X \subset \mathrm{pv}$ vesicatoria. Fig 7 fijada con glutaraldehído al $5 \%$, las restantes, fijadas por congelación a $-20^{\circ} \mathrm{C}$. Escala: Barras: $10 \mu \mathrm{m}$.

Fig 3. Bacterias cercanas a un estoma de la cara adaxial de la hoja, a las 2 h de la inoculación.

Fig 4. Bacterias sobre un estoma cerrado de la cara abaxial. A las $20 \mathrm{~h}$, ya no hay bacterias en el haz.

Fig 5. Bacterias en el interior de los tricomas deteriorados (colapsados) dónde quedan protegidas $(20 \mathrm{~h})$.

A los 13 días aparecieron síntomas macroscópicos en el haz, quedando la infección visible en ambas caras de las hojas.
A los 14 días, las bacterias tapizaron completamente la superficie foliácea en el área de la lesión, ubicándose en las proximidades de los estomas y sobre la base de los tricomas que ya estaban colapsados y se desprendían de la hoja (fig 8). Las bacterias se hallaban aglutinadas en grandes masas, pero manteniendo su individualidad.

A los 16 días, sobresalen zonas en el área correspondiente a la mancha y no se observaron bacterias en la misma pero sí en la zona limítrofe entre tejido sano y enfermo, saliendo por los estomas, aglomeradas por una sustancia mucosa $y$, en las cercanías de los mismos.

A los 21 días, las bacterias continuaron su ciclo de salida por los estomas aglutinadas en forma de cúmulos (fig 9). En el envés, se observaron bacterias sobre toda la superficie, particularmente en los restos de los tricomas desintegrados y en las depresiones de las nervaduras dañadas por el patógeno (fig 10).

Durante toda la experiencia, hubo mayor cantidad de bacterias sobre el envés de las hojas que sobre el haz.

Los 2 híbridos de tomate inoculados, mostraron una secuencia similar de aparición de síntomas y eventos posteriores, no obstante, "Leo" presentó lesiones de mayor tamaño que "Carmelo".

\section{Determinación de la actividad enzimática in vitro}

Las 42 cepas de $X c$ pv vesicatoria degradaron celulosa en el medio CM-3 lo cual se puso de manifiesto con la formación de halos translúcidos alrededor de las colonias sobre el fondo del medio de cultivo que permaneció teñido de rojo, indicando la presencia de celulasa.

Todos los cultivos desarrollaron normalmente en medio D5, lo que significa que podían utilizar celobiosa como única fuente carbonada.

Todas las cepas hidrolizaron Tween 80 indicando que producen lipasas.

\section{DISCUSION}

Inmediatamente después de la pulverización, las células bacterianas se dispersaron al azar sobre la superficie de las hojas, para posteriormente localizarse sobre o cerca de los estomas, primero 

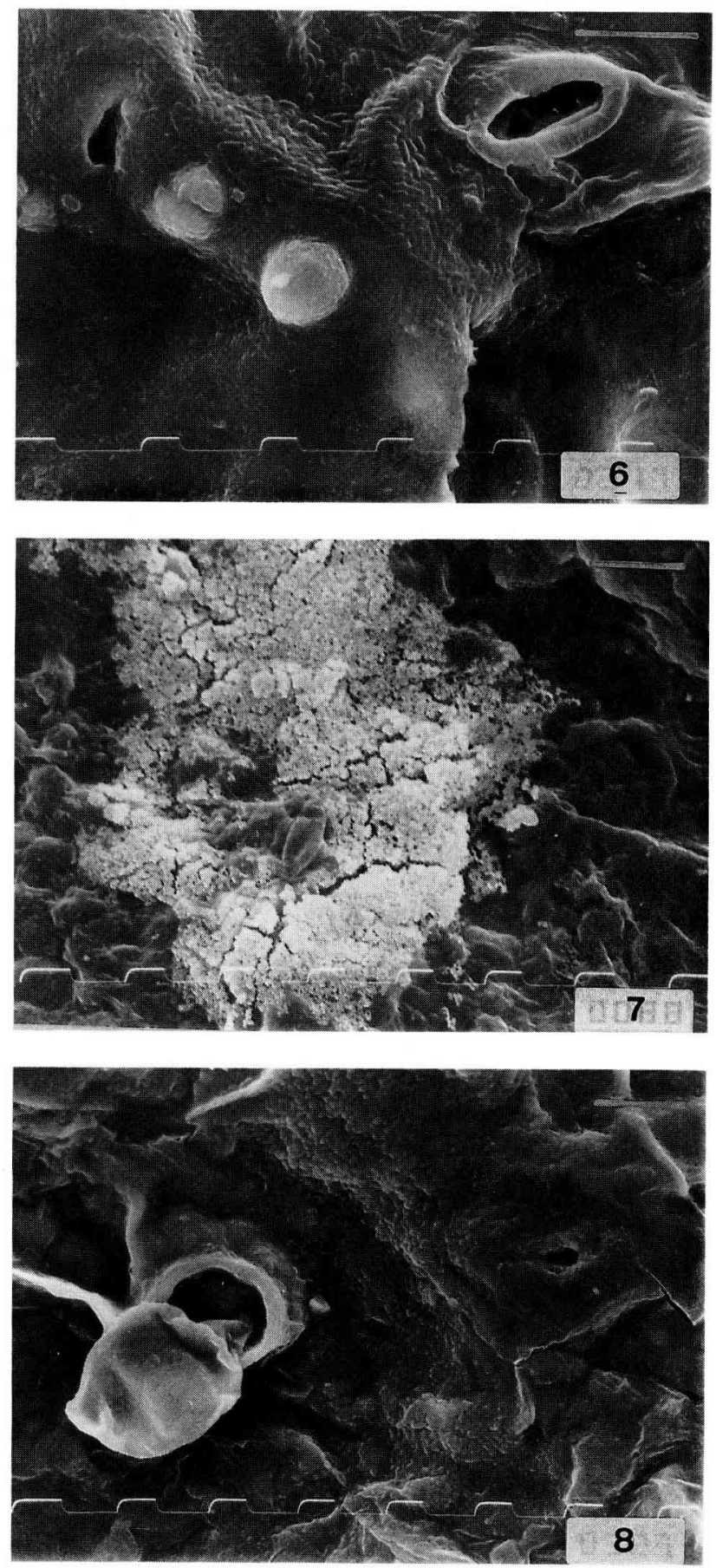

Fig 6. Exudado bacteriano expulsado a través de los estomas y grandes masas bacterianas aglutinadas sobre la superficie de la hoja. Solamente hay síntomas visibles de la enfermedad en la cara inferior ( 6 días).

Fig 7. Material granular en el área de la lesión (cara inferior), el tejido vegetal se ve muy deteriorado ( 8 días).

Fig 8. Bacterias tapizando la superficie foliácea, cubriendo completamente a los estomas y en la base de un tricoma deteriorado (13 dias). Hay lesiones cubiertas por bacterias en ambas caras de las hojas.

de la cara adaxial y luego de la cara abaxial. A los 3 días, las bacterias desaparecieron totalmente de la superficie foliacea completando su
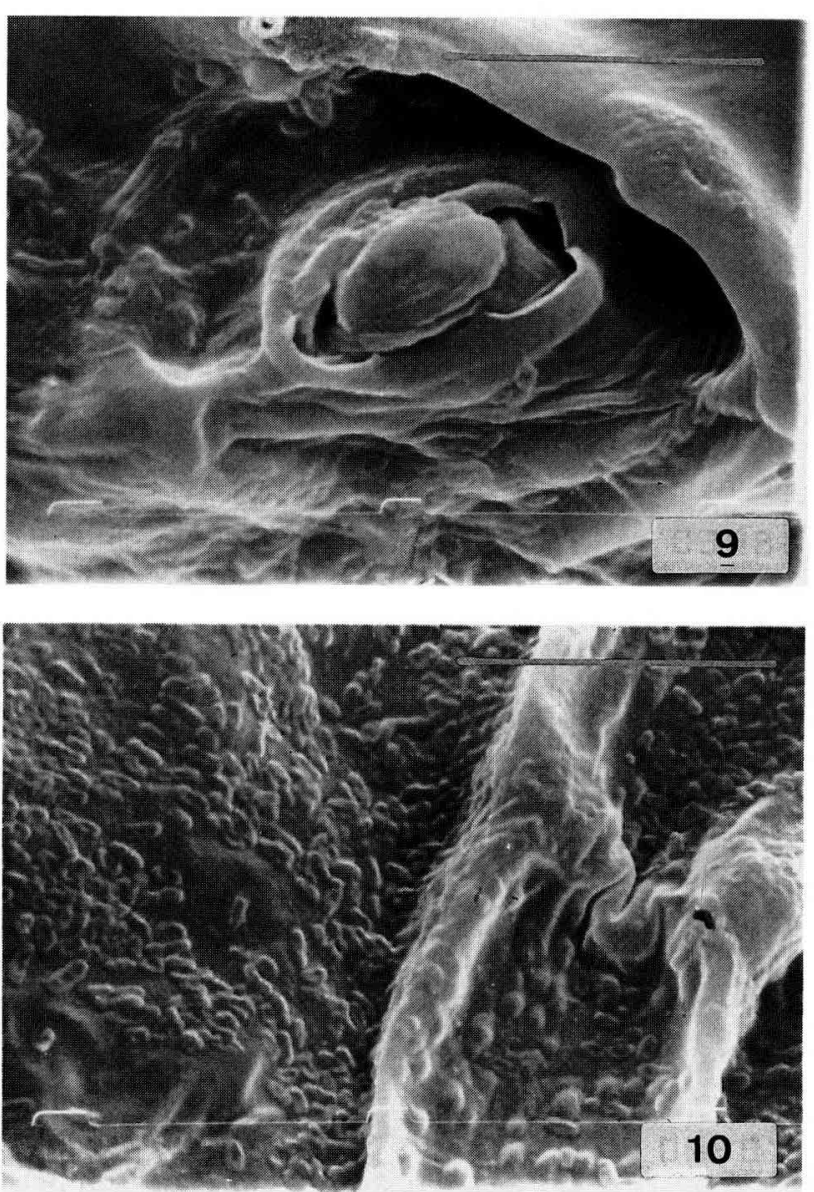

Fig 9. Exudado bacteriano saliendo por un estoma (21 días).

Fig 10. Bacterias en una masa compacta sobre la superficie foliácea de la cara inferior de la hoja y dentro de las nervaduras deterioradas.

ciclo de penetración por vía estomática y, adicionalmente, por la base de los tricomas deteriorados.

La fuerte atracción por parte del estoma podría deberse a un fenómeno de cargas eléctricas. Las bacterias que se suspenden en soluciones de electrolitos poseen cargas superficiales negativas (Marshall, 1967) y los estomas están cargados eléctricamente en forma positiva (Montaldi E, Com Pers), dado que existe un flujo de protones hacia las células oclusivas durante los momentos previos a la apertura de las mismas (Edwards et al, 1988). Cuando el estoma permanece abierto, hay una acumulación de $\mathrm{K}^{+}$en las células guardianas. Se ha demostrado que dichas células extrudan $\mathrm{H}^{+}$y el $\mathrm{K}^{+}$es intercambiado por protones (Raschke y Humble, 1973).

Ramos y Volin (1987) demostraron la importancia de los estomas como aberturas naturales 
en la infección de hojas de tomate y otras especies de Lycopersicon inoculadas con $X c$ pv vesicatoria. El porcentaje de infección y el tamaño de las lesiones se vieron reducidos en forma significativa cuando los estomas permanecían cerrados artificialmente en plantas mantenidas en la oscuridad o tratadas con antitranspirantes como el ácido absícico y el acetato de fenilmercurio. Dichos autores, también determinaron que existía una relación directa entre la frecuencia de estomas (número de estomas $/ \mathrm{cm}^{2}$ de hoja) y el número de lesiones por unidad de superficie, concluyendo que los híbridos de tomate con mayor cantidad de estomas por $\mathrm{cm}^{2}$ de hoja, eran más susceptibles a la enfermedad. La misma relación se daba con respecto a las hojas más jóvenes debido a que poseen una mayor frecuencia estomática que las adultas.

El empleo de antitranspirantes redujo significativamente la incidencia de la enfermedad en aquellas plantas inoculadas por pulverización pero no en las inoculadas por infiltración, esto explicaría que el bajo nivel de infección de algunos híbridos estaría relacionado con una resistencia de tipo morfológico configurada por un menor número de estomas por unidad de superficie (Ramos y Volin, 1987).

Una vez que penetraban por los estomas, las bacterias se localizaban en las cámaras subestomáticas dónde se multiplicaban abundantemente y, desde allí, se diseminaban por los espacios intercelulares del parénquima esponjoso del mesófilo. Esto tendría un significado epidemiológico puesto que la cámara subestomática les brindaría protección y les permitiría multiplicarse abundantemente para salir nuevamente por los estomas en forma de cúmulos asociadas a una sustancia de tipo mucoso que las aglutina en la superficie de la hoja apareciendo nuevas fuentes de inóculo y de posterior infección. Este mismo comportamiento fue observado por distintos investigadores en diversos patovares de Pseudomonas syringae: $P$ s pv syringae (Roos y Hattingh, 1987b; Mansvelt y Hattingh 1987, 1989; Hatting et al, 1989), $P$ s pv mors-prunorum (Roos y Hatting, 1987a), $P s$ pv tomato (Devash et al, 1980; Bashan et al, 1981; Getz et al, 1983; Perez et al, 1987); en patovares de Xanthomonas campestris: $X c \mathrm{pv}$ manihotis (Verdier et al, 1990), $X$ c pv pruni (Miles et al, 1977; Duplessis, 1990 ) y en otras especies bacterianas (Pruvost y Gardan, 1988).

La mayor concentración bacteriana en la cara inferior de las hojas puede deberse al mayor número de estomas por unidad de superficie exis- tente con relación a la cara superior. Dichos estomas, junto con sus cavidades subestomáticas se constituirían en el nicho ecológico preferido por el patógeno para luego colonizar los tejidos del hospedante. Otra ventaja de la cara adaxial sería ofrecer un microclima más favorable para la supervivencia y multiplicación bacteriana, debido a una menor exposición a los rayos UV y a un mayor contenido de humedad superficial.

Cuando $X c$ pv vesicatoria se multiplica en los espacios intercelulares del parénquima foliáceo, degradaría las sustancias pécticas constitutivas de la laminilla media, por medio de la acción de distintos tipos de poligalacturonasas (Dye, 1960); pectin metil esterasas (Dye, 1960; Starr y Nasuno, 1967) o protopectinasas (Dye, 1960). Los sustratos pécticos de la laminilla media serían los sitios primarios de maceración del tejido por acción de ciertas poligalacturonasas, como las poligalacturonato-liasas. Esta actividad enzimática se debería parcialmente a la bacteria y parcialmente a la interación patógenohospedante como determinaron Bashan et al (1985) en el caso de Pseudomonas syringae pv tomato.

Una vez que las células de la laminilla media se separan, el patógeno seguiría actuando sobre los materiales de las paredes celulares mediante la producción de enzimas celulolíticas. $X c \mathrm{pv} v e-$ sicatoria produce celulasas in vitro de acuerdo con lo determinado en el medio CM-3 y corroborado por otros investigadores (Gitaitis et al, 1987) y posee la capacidad de degradar celobiosa mediante la acción de la $\beta$-glicosidasa (Wood, 1960). La mayoría de los patovares de $X$ campestris pueden utilizar celobiosa como única fuente carbonada, demostrado por su crecimiento en el medio $D_{5}$ (Kado y Heskett, 1970). Todas las cepas de $X c \mathrm{pv}$ vesicatoria ensayadas, se desarrollaron normalmente en dicho medio. EF segundo paso, sería la degradación de los componentes de las paredes celulares de la epidermis por acción de las poligalacturonasas sobre los ácidos pécticos y pectínicos y el proceso continuaría de la misma forma que se señaló para con las células parenquimáticas. El patógeno actuaría in vivo degradando las paredes celulares del hospedante por acción de celulasas, $\beta$ glicosidasas, pectin metil esterasas, poligalaturonasas y/o protopectinasas, lo cual resultaría en una separación y posterior colapso de las células. En estadios posteriores, el protoplasto sería atacado en forma directa, con la consiguiente pérdida de su integridad funcional y daño de las membranas celulares que, debido a su alto 
contenido lipídico podrían ser alteradas por la producción de lipasas por parte del patógeno, tal como se determinó en el medio de Sierra. Es importante destacar que la producción de enzimas pécticas, celulolíticas y lipolíticas in vitro por parte de $X c \mathrm{pv}$ vesicatoria, no puede tomarse como evidencia conclusiva de su acción en el proceso de patogénesis. Los resultados obtenidos de esta forma deberían corroborarse con su efecto en planta debido a que aún no está aclarado si las enzimas producidas por el patógeno o por la relación huésped-patógeno juegan el papel más importante en la colonización bacteriana de los tejidos vegetales o si simplemente se producen como consecuencia de otros procesos fisiológicos de origen desconocido y que ocurrirían con posterioridad a la penetración.

Un detalle interesante, observado mediante microscopía electrónica de barrido, fue la aparición de un material de aspecto granuloso localizado en el área de las lesiones que resultó similar al descripto por Lawson et al (1989) sobre hojas de lima inoculadas con distintas cepas de Xanthomonas campestris pv citri mediante lesión de los tejidos. Estos autores determinaron que la cepa XC 90 inducía la formación de grandes lesiones que resultaban en una protrusión de las células del hospedante a través de la superficie epidérmica, debido a una estimulación de la división celular en la zona cercana a la lesión, generándose un tejido equivalente a una peridermis (Lawson et al, 1989).

Restaría establecer, mediante estudios posteriores, si la aparición de ese tejido anormal se debe a la producción por parte de la bacteria o de la planta estimulada por la bacteria de algún regulador de crecimiento $u$ otra sustancia de tipo hormonal que induciría la formación del mismo.

\section{AGRADECIMIENTOS}

A los técnicos del Servicio de Microscopía Electrónica de Barrido del Museo de Ciencias Naturales, UNLP, P Sarmiento y R Urréjola.

\section{REFERENCIAS}

Bashan Y, Okon Y, Henis (1985) Detection of cutinases and pectic enzymes during infection of tomato by Pseudomonas syringae pv tomato. Phytopathology 75, 940-945

Bashan Y, Sharon E, Okon Y, Henis H (1981) Scanning electron and light microscopy of infection and symptom development in tomato leaves infected with Pseudomonas tomato. Physiol Plant Pathol 19, 139-144
Devash Y, Okon Y, Henis Y (1980) Survival of Pseudomonas tomato in soil and seeds. Phytopathol $Z$ 99, 175-185

Duplessis HJ (1990) Systemic invasion of plum seed and fruit by Xanthomonas campestris pv pruni through stalks. Phytopathol Z 130, 37-45

Dye DW (1960) Pectolytic activity in Xanthomonas. $N Z J$ Sci 3, 61-69

Edwards MC, Smith GN, Bowling DJF (1988) Guard cells extruded protons prior to stomatal opening. A study using fluorescence microscopy and $\mathrm{pH} \mathrm{mi-}$ croolectrodes. J Exp Bot 39, 1541-1547

Getz S, Fulbright DW, Stephens CT (1983) Scanning electron microscopy of infection sites and lesion development of tomato fruit infected with Pseudomonas syringae pv tomato. Phytopathology 73, 39-43

Gitaitis RD, Sasser MJ, Beaver RW, Mc Innes TB, Stall RE (1987) Pectolytic xanthomonads in mixed infections with Pseudomonas syringae pv syringae, Pseudomonas syringae pv tomato and Xanthomonas campestris pv vesicatoria in tomato and pepper transplants. Phytopathology 77, 611-615

Guo A, Leach JE (1989) Examination of rice hydathode water pores exposed to Xanthomonas campestris pv oryzae. Phytopathology 79, 433-436

Hattingh MJ, Roos IMM, Mansvelt EL (1989) Infection and systemic invasion of deciduous fruit trees by Pseudomonas syringae in South Africa. Plant Dis 73, 784-789

Hayward AC (1960) A method for characterizing Pseudomonas solanacearum. Nature (Lond) 186, 405-406

Hayward AC (1983) Preliminary diagnosis of Plant Diseases caused by Bacteria . In: Plant bacterial diseases. A diagnostic guide (Fahy PC, Persley GJ, eds) Acad Press, Sydney

Hayward AC, Waterston JM (1964) Xanthomonas vesicatoria. CMI Descriptions of Pathogenic Fungi and Bacteria No 20

Huang JS (1986) Ultrastructure of bacterial penetration in plants. Annu Rev Phytopathol 24, 141-157

Johansen DA (1940) Plant Microtechnique. Mc GrawHill Book Co, Inc, New York

Kado Cl, Heskett MG (1970) Selective media for isolation of Agrobacterium; Corynebacterium; Erwinia; Pseudomonas and Xanthomonas. Phytopathology 60, 969-976

Lawson RH, Dienelt MM, Civerolo EL (1989) Histopathology of Xanthomonas campestris pv citri from Florida and Mexico in wound-inoculated detached leaves of Citrus aurantifolia: light and scanning electron microscopy. Phytopathology 79, 329-335

Liao CH, Wells JM (1987) Association of pectolytic strains of Xanthomonas campestris with soft roots of fruit and vegetables at retail markets. Phytopathology 77, 418-422

Mansvelt EL, Hattingh MJ (1987) Scanning electron microscopy of colonization of pear leaves by Pseudomonas syringae pv syringae. Can $J$ Bot 65 , 2517-2522 
Mansvelt EL, Hattingh MJ (1989) Scanning electron microscopy of invasion of apple leaves and blossoms by Pseudomonas syringae pv syringae. Appl Environ Microbiol 55, 533-538

Marshall KC (1967) Electrophoretic properties of fastand slow-growing species of Rhizobium. Aust J Biol Sci $20,429-438$

Mew TW, Mew IC, Huang JS (1984) Scanning electron microscopy of virulent and avirulent strains of Xanthomonas campestris pv oryzae on rice leaves. Phytopathology 74, 635-641

Miles WG, Daines RH, Rue JW (1977) Presymptomatic egress of Xanthomonas pruni from infected peach leaves. Phytopathology 67, 895-897

Perez JM, Pennypacker SP, Lukezic FL (1987) Direct penetration of tomato leaves by Pseudomonas syringae pv tomato. Phytopathology 77, 988

Petrolini B, Quaroni S, Saracchi M (1986) Scanning electron microscopy investigation on the relationships between bacteria and plant tissues. I. Comparative techniques for specimen preparation. Riv Patol Vet 5 IV 22, 7-15

Pruvost O, Gardan L (1988) Étude de l'implantation épiphylle de Xanthomonas campestris pv corylina, Xanthomonas campestris pv juglandis, Erwinia herbicola et Pseudomonas paucimobilis sur feuilles de noisetier. Agronomie 8, 925-932

Ramos LJ, Volin RB (1987) Role of stomatal opening and frequency of infection of Lycopersicon spp by Xanthomonas campestris pv vesicatoria. Phytopathology 77, 1311-1317

Raschke K, Humble GD (1973) No uptake of anions required by opening stomata of Vicia faba: guard cells release hydrogen ions. Planta 115, 47-57
Roos IMM, Hattingh MJ (1987a) Systemic invasion of cherry leaves and petioles by Pseudomonas syringae pv mors-prunorum. Phytopathology 77, 12461252

Roos IM, Hattingh MJ (1987b) Systemic invasion of plum trees and shoots by Pseudomonas syringae pv syringae introduced into petioles. Phytopathology $77,1253-1257$

Sierra $G$ (1957) A simple method for the detection of lipolytic activity of microorganisms and some observations of the influence of the contact between cells and fatty susbtrates. Leuvenhoek J Microbiol Serol $23,15-22$

Starr MP, Nasuno S (1967) Pectolytic activity of phytopathogenic Xanthomonas. J Gen Microbiol 46, 425433

Tsuno K, Wakimoto S (1988) Ultrastructural changes in the early stages of interaction between rice leaf parenchymatous tissue and infiltrated bacteria. Ann Phytopathol Soc Jpn 54, 32-44

Tsuno K, Wakimoto $S$ (1989) Ultrastructural study on the compatibility between rice leaf vessel system and various bacteria. Proc 7th Int Conf Plant Pathol Bact, Budapest, Hungary, pg, 45-50

Vakili NG (1967) Importance of wounds in bacterial spot Xanthomonas vesicatoria of tomatoes in the field. Phytopathology 57, 1099-1103

Verdier V, Schmit J, Lemattre M (1990) Étude en microscopie électronique à balayage de l'installation de deux souches de Xanthomonas campestris pv manihotis sur feuilles de vitroplants de manioc. Agronomie 2, 93-102

Wood RKS (1960) Pectic and cellulolytic enzymes in plant disease. Annu Rev Plant Physiol 11, 299-322 